\title{
The role of groundwater in the management of water resources in the World
}

\author{
ANTÓNIO CHAMBEL \\ Departamento de Geociências, Universidade de Évora, Instituto de Ciências da Terra (ICT), Pólo da Universidade de \\ Évora, Rua Romão Ramalho, 59, 7000-671 Évora, Portugal \\ achambel@uevora.pt
}

\section{BACKGROUND}

Groundwater forms about $98 \%$ of all the fresh liquid water available in the World. Even so, groundwater is the forgotten and most ignored part of the water cycle. Any time a drop of water infiltrates into the soil, it enters an occult world where still today many mysteries need to be solved. Studies can sometimes prove the journey of water under the soil, from the infiltration point to a discharge point, but it is practically impossible to know the exact path of this drop along the subterranean journey. The same is true for groundwater quality. The infiltrating water begins to interact chemically with the soil particles immediately it enters the soil, within the unsaturated zone. When it enters the saturated zone (aquifer) it interacts with the rock and weathered materials, dissolving minerals, interchanging ions, depositing in other places previously dissolved substances, in a permanent change that includes interaction with human activities, be it capture by a pump in a well or the contamination caused by infiltrating residual water from agriculture or a sewage system.

Interaction with surface water systems is basic for life on Earth, for both plants and animals depending on water. With its capacity to regulate the water flow in the World, groundwater is responsible for the presence of surface water in many arid and semi-arid regions of the World during the driest season. In fact, the water in rivers flows at velocities much higher than in most parts of the aquifers, and sometimes the groundwater flow is so slow that rainwater infiltrated in the soil returns to the superficial water system months or even years after infiltration, sometimes bringing water to rivers during periods of severe dryness. Such regulatory control needs more study and attention from the regulators and users, since any disequilibrium in these fragile systems can affect all dependent life. This is particularly true for countries with a Mediterranean climate influence.

In relation to quantity, groundwater is normally under stress in countries with lack of surface water, a high imbalance between the rainy season and the dry season, and strong rates of evapotranspiration. The stress is also more common in highly developed countries, and in less developed countries with high rates of current development. Of these countries, there are some where groundwater is still renewable and where two types of situation can occur: those where the quantity of abstracted water is less than the average infiltration rate and the resource is still sustainable, and those where the abstraction rates have long exceeded the infiltration rates. In the latter case, the resource is not sustainable in the future and other related issues can happen, such as land subsidence problems following the depletion of groundwater resources.

But there are countries in desert areas in which the rain is so scarce that practically no recharge is possible. In these climatic environments, the abstracted groundwater is actually fossil water, infiltrated thousands of years ago, and this abstraction must be considered "water mining". In this case, groundwater must be considered as any other geological resource, non-renewable for many generations to come.

In some of the less developed countries the situation is not so desperate, but it is just a matter of time. Currently, the actual economic conditions do not permit the use of drilling techniques, and deficiencies in the supply of energy do not permit the high costs of abstraction. Once this situation is solved in these countries, the pressure on the aquifers will begin, as happened before in other countries.

In relation to quality, a fraction of groundwater does not have natural quality adequate for water supply or for use in agriculture. This can be the result of several processes, such as the water retained in the geological formations when the rock was formed (many of the rocks that form aquifers were 
created under the sea), the interaction between water, soil and rock (depending on the type of rock and its weathering) and the time of contact between water and rock (the longer the time, the greater the possibility of brackish water in the geological formations). Of all the groundwater considered to be of good quality for use in human activities, a part is now contaminated by human activities.

It is known that groundwater is naturally protected from contamination much more than surface water. During the infiltration process, the interaction and the filtration processes of the soil and weathering materials of the rock matrix filter and retain a part of the contaminants. After entering the aquifer, the permanent interaction, the filtering capacity of the aquifer, the chemical and biological degradation of some pollutants is also important. But, in the end, if an aquifer is strongly contaminated, it will be much more difficult and expensive to remediate than the surface streams.

\section{RECOMMENDATIONS FOR THE FUTURE}

Groundwater has a regulatory role in the water cycle. Its capacity of resilience, its natural defences against pollution, the timings of its flow and the huge capacity of storage of some rocks make groundwater a vital part of the water cycle which needs protection and intelligent management. The actual threats to groundwater resources often result from the ignorance of the functioning of groundwater systems by decision makers and managers, and the poor representation of groundwater specialists in the world of water management. The threats to groundwater involve its uncontrolled abstraction and use, and the contamination of the resource. Groundwater needs:

- Monitoring: in most of the aquifers in the World, groundwater monitoring is still deficient; water levels and chemical monitoring are essential to understand the behaviour and degree of human impact on groundwater resources.

- Protection: depending on the type of aquifer and its geological cover, the activities at the surface must be controlled; special attention to dense urban concentrations, agriculture and heavy industry (contamination and overexploitation); protection of recharge areas is essential, and also the correct management of coastal areas to avoid saline intrusion; with a few controlled exceptions, abstraction must never exceed 80 to $90 \%$ of the annual infiltration rate, maintaining some resources to sustain the environmental needs.

- Remediation: for already contaminated aquifers, studies must be made, the pollution origins controlled, and remediation measures taken, all combined with strong surveillance through specific monitoring.

- Integrated management: groundwater and surface water must be managed together, as two parts of the same cycle; in hot climates surface water can have major quality problems during the hottest months, but the aquifers, maintaining a much more controlled temperature, can be a solution for water supply during the hottest months; surface water can be used more during the rainy season, when aquifers are recharging.

- To be recognized as a vital resource for the environment: as a regulator of water flow, groundwater discharge to springs, rivers, lakes or even to the sea, creates the conditions for the survival or reproduction of numerous plants and animals, forming sometimes specific and important ecosystems essential for the survival of many important species in the World.

- To be involved in the environmental education: education is the basis for a better future in all aspects of life, but groundwater has been neglected or even forgotten in many water-related campaigns.

Groundwater is essential for life, be it the life of animals, plants or human beings. Knowledge is basic to protect, manage and preserve.

Acknowledgement The author acknowledges the funding provided by the Évora Geophysics Centre, Portugal, under the contract with FCT (the Portuguese Science and Technology Foundation), PEst-OE/CTE/UI0078/2014. 